\title{
El Parménides de Platón y la comprensión del Uno en la filosofía de Plotino: ¿un olvido de Heidegger?
}

\section{Plato's Parmenides and understanding the One in the philosophy of Plotinus: an oversight by Heidegger?}

\author{
María Jesús Hermoso FÉLIX \\ (Universidad de Valladolid)
}

Recibido: 30/10/2015

Aceptado: 05/04/2016

\section{Resumen}

El presente artículo se centra en el estudio de la exégesis que lleva a cabo Plotino en torno a la significación de la inefabilidad del uno, planteada en el Parménides platónico al hilo de la primera hipótesis. Este ubica a este primer uno inefable en el centro mismo de su sistema, lo que tendrá fuertes implicaciones tanto a nivel ontológico como por lo que respecta a la comprensión del lenguaje. La concepción de la realidad que se deriva de esta inefabilidad del primer principio, de un lado, y las implicaciones en la naturaleza del lenguaje filosófico que abre este postulado, de otro, ocuparán la centralidad de nuestras reflexiones. Atenderemos a los textos originales en los que se plantea la cuestión, apoyándonos en la labor de la crítica, discutiendo los puntos fundamentales a fin de esclarecer la posición que encontramos en las Enéadas. Tomaremos, asimismo, en consideración la actualidad que tiene esta posición y su capacidad de ir más allá de la crítica heideggeriana a la metafísica.

Palabras clave: Platón, Parménides, neoplatonismo, Enéadas, Plotino, uno, ontología, lenguaje, Heidegger.

\section{Abstract}

The present article focuses on the study of the exegesis by Plotinus with regard to the meaning of the ineffability of the one provided in Plato's Parmenides in the 
first hypothesis. He places this first ineffable one at the very centre of his system, which would have important implications from both an ontological point of view and with regard to understanding the language. The conception of reality that derives from the ineffability of the first principle and the implications for the nature of philosophical language that this postulate raises will be the centre of our reflections. To shed light on the position set down in the Enneads, we will review the key points based on the original texts that deal with this issue and related critical works. We will also look at the contemporary relevance of this position and its ability to go beyond the Heideggerian critique of metaphysics.

Keywords: Plato, Parmenides, neoplatonism, Enneads, Plotinus, one, ontology, language, Heidegger.

\section{Introducción}

Quizá sea el Parménides uno de los diálogos más complejos de Platón, transido de paradojas y laberintos conceptuales. La búsqueda del sentido interno de este diálogo ha constituido y sigue constituyendo uno de los grandes retos a los que nos enfrenta la comprensión de la obra platónica. No es nuestra intención adentrarnos en los muchos aspectos presentes en esta difícil tarea hermenéutica sino tomar apenas uno de ellos, trazando algunas de sus implicaciones en la tradición neoplatónica, a través de la figura de Plotino.

La centralidad de este diálogo para la conformación misma del marco conceptual del Neoplatonismo ya desde Plotino es de sobra conocida. Como apunta Trouillard, los neoplatónicos a partir de Plotino demandan al Parménides el secreto del platonismo: "Incluso si discrepan en la interpretación de las hipótesis, todos creen que nadie es platónico si no afronta el misterio del uno en este diálogo"1. La interpretación de las diferentes hipótesis toma para ellos un valor ontológico, la realidad entera y sus principios constitutivos son desplegados en la sucesión misma de las hipótesis. Una ontología, una teología y una epistemología son perfiladas a partir de la labor hermenéutica acometida sobre este complejo diálogo. Allí donde la compresión del uno se muestra atravesada de negación y afirmación en una enigmática convergencia creadora, asistimos al emerger del sentido mismo de la realidad, en su condición intrínsecamente dinámica y paradójica.

Nuestro estudio vendrá a centrarse en uno de los aspectos de esta labor hermenéutica acometida por el pensamiento neoplatónico sobre este diálogo: La significación de la inefabilidad del uno planteada en el pasaje 142 a, al hilo de la primera

\footnotetext{
1 Trouillard J. L'un et l'âme selon Proclos. París : Les Belles Lettres, 1972, p. 111.
} 
hipótesis. Trataremos de atender a sus implicaciones en el pensamiento de Plotino, buscando trazar sus consecuencias en el ámbito ontológico y en la comprensión del lenguaje. La concepción de la realidad que se deriva de esta inefabilidad del primer principio, de un lado, y las implicaciones en la naturaleza del lenguaje filosófico que abre este postulado, de otro, ocuparán la centralidad de nuestras reflexiones. La comprensión del lenguaje que sostiene este marco teórico se mostrará decisiva a la hora de calibrar la disposición hermenéutica que debe ser desplegada para promover una correcta interpretación de los textos.

\section{Implicaciones ontológicas de la inefabilidad del primer principio}

A lo largo del Parménides, las diferentes hipótesis se van conjugando con la imposibilidad de conocimiento de lo uno o con la posibilidad de su conocimiento, según se considere lo uno como determinado o como desvinculado de toda determinación ${ }^{2}$. Así, en 142a se extrae la consecuencia epistémica de la negación respecto de lo uno de cualquier determinación, en tanto desvinculado del ser y apartado de la participación en el mismo. Si "de ningún modo lo uno participa del ser"3, afirma Platón, "tampoco hay modo de que sea uno; pues sería ya algo que es y que participa del ser. Pero, según parece, lo uno ni es uno ni es, si ha de darse crédito a esta argumentación"4. La consecuencia epistémica es clara: “-Por lo tanto, no hay para él ni nombre ni enunciado, ni ciencia, ni sensación ni opinión que le correspondan. [...]-Tampoco, entonces, se lo nombra ni se lo enuncia ni es objeto de opinión ni se lo conoce ni hay ningún ser que de él tenga sensación" 5 .

Lo uno en este primer argumento es desvinculado del ser y en esta desvinculación emerge, necesariamente, la inefabilidad propia de aquello que no es un "algo

\footnotetext{
2 Cf. comparativamente los pasajes 142 a, 155 d, 160 d y 164 b. El carácter epistémico que acompaña a cada una de las hipótesis es intrínsecamente dinámico. Apunta fundamentalmente a la necesidad del ser, de la multiplicidad y de la determinación para poder predicar algo sobre algo. Para que algo sea cognoscible ha de ser comprendido como "un algo" y "un algo determinado". En este marco, esencialmente paradójico, lo uno, dependiendo de la perspectiva, aparecerá, de modo dinámico, como inefable, como cognoscible y como la condición misma de la multiplicidad y del conocimiento. Tal será la afirmación en la que Platón resume esta enigmática y compleja reflexión sobre lo uno en 166

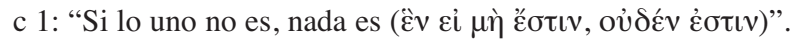

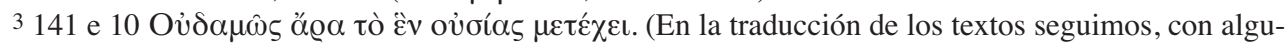
na pequeña variación, la versión castellana reseñada, en cada caso, en la bibliografía).

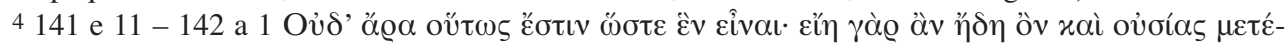

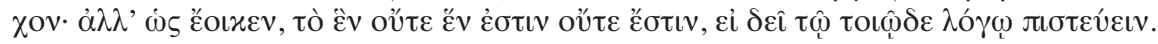

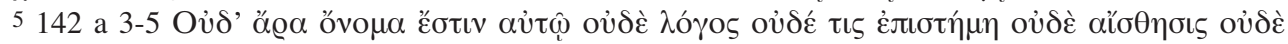

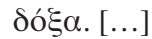

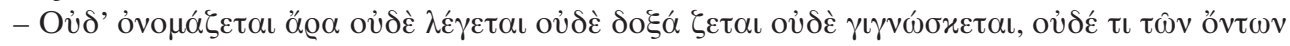

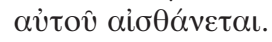


determinado". Lo uno, más allá de toda determinación no puede ser concebido como objeto de conocimiento, puesto que en modo alguno queda delimitado por determinación alguna. Toda relación dual queda descartada y, con ella, la condición de posibilidad de la predicación, de la ciencia, de la sensación o de la opinión. Nada hay que pueda ser predicado, ni nada que pueda ser configurado por la investigación científica, ni nada que pueda ser sentido por un sujeto como algo distinto, ni cabe opinión en lo que escapa a estas categorías. El hombre se ve desfondado en cada una de sus potencias por una noción de lo uno que trasciende el lenguaje, la ciencia, la opinión y la sensación.

Las consecuencias de la lectura que Plotino lleva a cabo de este pasaje del Parménides platónico serán determinantes en su filosofía. Éste verá al principio primero de toda realidad en esta primera hipótesis ${ }^{6}$, haciendo gravitar cada una de sus reflexiones en torno a este pilar fundamental que sostiene la arquitectónica entera de su pensamiento. Aquello que trasciende toda categoría del pensar, aquello que trasciende todas las potencias de lo humano es situado por Plotino en el centro mismo de su filosofía. En Enéadas V 4.1.10-15 leemos:

\footnotetext{
6 Como apunta Rist ("The Neoplatonic One and Plato's Parmenides", Transactions and Proceedings of the American Philological Association, Vol. 93, 1962, pp. 389), la demostración que lleva a cabo Dodds en su estudio ya clásico "The Parmenides of Plato and the origin of the neoplatonic One" (The Classical Quarterly, Vol. 22, n ${ }^{\circ} 3 / 4,1928$, pp. 129-142) es universalmente aceptada por la crítica. Dodds demuestra la dependencia del Uno de Plotino de la interpretación de la primera hipótesis del Parménides. Sus argumentaciones y los pasajes que alega (op. cit. pp. 132-133) dejan poco margen a la duda. Incluso É. Bréhier ("Le Parménide de Platon et la Théologie négative de Plotin", en Études de Philosophie Antique. París: Presses Universitaires de France, 1955, pp. 232) afirma que, a este respecto, Dodds tiene la batalla ganada. Este cuestiona con razones sólidas lo que denomina "la moda de las explicaciones orientalizantes" y apunta a la necesidad de trazar una línea dentro del propio pensamiento griego para dar razón de uno de los puntos nucleares del pensamiento de Plotino. Llega, entonces, a la fuente platónica y a una interpretación de la misma que remontaría, al menos, al neopitagórico Moderatus. Bréhier, por su parte, apunta a otro factor difícil de rebatir: Si bien "el origen parmenídeo del Uno plotiniano, en tanto que inefable e imposible de designar sino por negaciones, queda bien demostrado", en la comprensión del Uno plotiniano hay más. El aspecto negativo del Uno en cuanto al conocimiento es el reverso de un aspecto positivo; el Primero es el centro de una vida afectiva "que Plotino considera de una riqueza y de un sabor incomparables". Bajo nuestro punto de vista, ambas posiciones manejan sólidas razones y ambas han de ser tomadas en cuenta simultáneamente. Como concluye É. Bréhier (op. cit. p. 236): "Las negaciones del Parménides se encuentran en Plotino, si bien no podemos afirmar con certeza que el conjunto, la doctrina del Principio Supremo derive del Parménides. No podemos desvincular estas negaciones de un contexto que no se encuentra en Platón y que les da un sentido nuevo". El genio propio de Plotino es incuestionable y el papel que en ello juegue una posible influencia oriental es una cuestión controvertida y difícil de determinar (cf. infra, n. 47). Del mismo modo, es incuestionable la centralidad del Parménides platónico como foco central de inspiración y como objeto de exégesis que late bajo la comprensión del Uno plotiniano.
} 
Atribuirle aún el predicado «uno» ha de ser falso, de él no hay «definición ni ciencia»7, de él es de quien se dice que está «más allá de la Esencia» ${ }^{8}$. Porque si no fuera simple, exento de toda coincidencia y composición y realmente uno, no sería Principio. ${ }^{9}$

Este pasaje nos muestra una de las claves de la lectura que Plotino hace de la primera hipótesis del Parménides platónico. Éste acomete una exégesis en la que viene a converger el carácter inefable de lo uno planteado en 142 a y la condición de Principio de lo real que Platón atribuye al Bien en la República ${ }^{10}$. Esta convergencia abre la vía a la comprensión de lo uno, en su carácter inefable, como principio ontológico supremo del que depende toda otra realidad. La conexión entre estos dos parámetros conforma una de las líneas de fuerza del pensamiento de Plotino con grandes implicaciones teóricas.

Una de estas implicaciones apunta al modo paradójico en que se da este proceso causal. Aquello que está más allá de la esencia se conforma en principio de la esencia, luego el Uno da lo que no tiene. Chrétien apunta acertadamente a esta conexión: La inefabilidad del Uno constituye la otra cara de la idea de que el Uno da lo que no tiene. La negación vinculada al Uno tiene un reverso positivo simultáneo a nivel ontológico, de modo que la inefabilidad del Uno "pone en juego tanto la palabra como la existencia"11. Todo aquello que viene detrás de él y que ha de ser negado de él es donado por él12. Lo que podríamos llamar la indigencia del Uno es la fuente de su generosidad, porque no tiene nada puede darlo todo y hacerlo subsistir: "Pues precisamente porque ninguna cosa había en él, por eso brotan todas de él, y precisamente para que el ente exista, por eso él mismo no es ente, sino Progenitor del ente. Y esta es la primera como procreación. Porque el uno siendo perfecto nada busca, nada posee."13

\footnotetext{
7 Pl. Prm. 142 a 3-4.

8 Pl. R. 509 b 9.

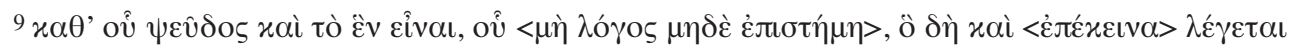

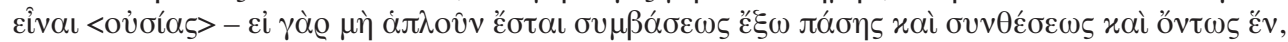

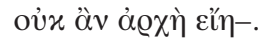

Cf. asimismo, En. V 1.8.1-7.

10 En R. 509 b 5-10 leemos: "Del mismo modo puedes afirmar que a las cosas inteligibles no solo les adviene por obra del bien su cualidad de inteligibles, sino que también se les añaden, por obra de aquél, el ser y la esencia; sin embargo, el bien no es esencia, sino algo que está todavía por encima de

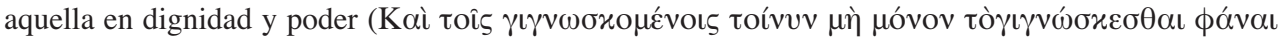

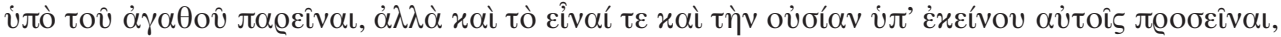

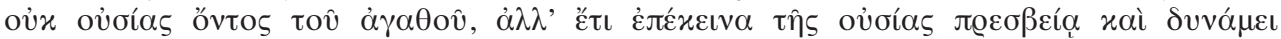

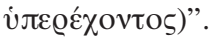

${ }_{11}$ Chrétien, J.L. "Le Bien donne ce qu'il n'a pas", Archives de Philosophie, n 43, 1980, p. 267, n. 11.

$12 \mathrm{Cf}$. entre otros textos, En. V 3.14.1-19.

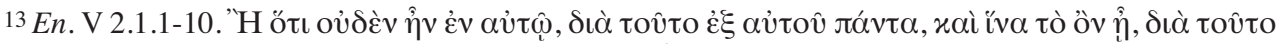

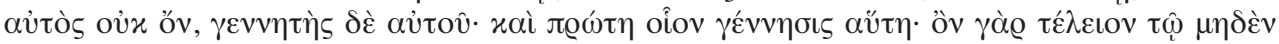

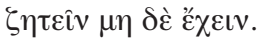


El Uno nada posee, no porque siendo él mismo "un algo determinado" no posea nada sino porque él mismo no es. Esta ausencia de posesión es el correlato de su inefabilidad. Aquello que nada posee se desborda, dando origen a otra cosa. El proceso por el cual es generada la realidad a este nivel goza de la misma inefabilidad que el Uno, o mejor dicho, forma parte de su propia inefabilidad: "Y es que aún el llamarle $<$ causa $>$ no es predicar algo que le sucede a él sino a nosotros" 14 afirma Plotino.

Podríamos decir, con Chrétien, que no hay propiamente producción en el Bien. Este es partidario de corregir ${ }^{15}$ los esquemas de difusividad del Bien por el principio de que el Bien da lo que no tiene. El no poseer nada es precisamente la otra cara de la sobreabundancia ${ }^{16}$. La generosidad del Bien sería no tanto una efusión como un retraerse para dejar ser. En la henología negativa hay un momento positivo: Todo lo que el Uno no es es simultáneamente un don del Uno, conforma realidad y una realidad autosuficiente 17: "Trascendiendo todas las cosas, fue capaz tanto de crearlas como de dejarlas ser por sí mismas"18. El Uno deja ser a la realidad que sin el Uno no sería, carecería de ser. El Uno no domina la realidad sino que la posibilita como realidad que se basta a sí misma. Acertadamente afirma Chrétien que: "el emplazamiento del principio sobre aquello que él mismo genera no expresa el promontorio abrumador de un despotismo, sino la libre altitud de un dejar ser"19.

En nuestra opinión se trataría no tanto de corregir los esquemas de difusividad del Bien que están presentes en multitud de pasajes de las Enéadas ${ }^{20}$ como de tener presente la inefabilidad del Uno como simultánea a todo lo que pueda decirse de él. La producción de la realidad a partir de un "no-ente", de un principio que no es "un algo determinado", hace que la comprensión misma de la producción haya de ser

\footnotetext{
14 En. VI 9.3.50.

15 Op. cit. p. 276. También Aubenque, en un sentido convergente, apunta a la necesidad de corregir lo que él denomina "la metáfora clásica de la causalidad". Incidiendo en que, efectivamente, la causalidad tiene un sentido ontológico y que un no-ente no puede ejercer causalidad en sentido estricto (Cf. Aubenque, P. "La superación neoplatónica de la Metafísica”, en ¿Hay que deconstruir la Metafísica? (trad. castellana Ayuso Díez, J.M.). Madrid: Encuentro, 2012, p. 50-51),

16 Sobre esta cuestión, cf. Zamora, J.M. La génesis de lo múltiple. Materia y mundo sensible en Plotino. Valladolid: Universidad de Valladolid, 2000, p. 196-199.

${ }^{17}$ En.V 3.17.10 "Si hace que cada uno exista y que, por la presencia del Uno, la pluralidad de la inteligencia y la inteligencia misma sea autosuficiente, está claro que aquél es el creador de la esencia y de la autosuficiencia, sin ser él mismo esencia, sino estando «más allá de la esencia» y más allá de la

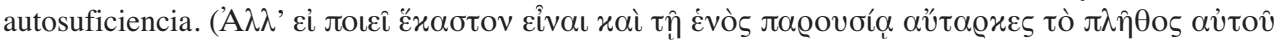

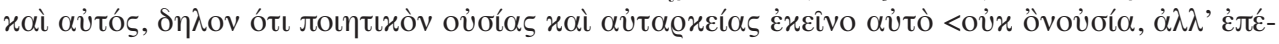

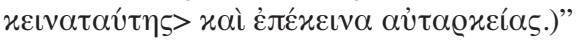

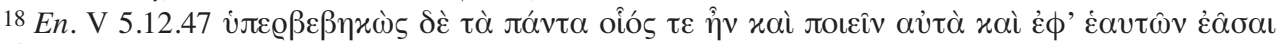
Eîvol

19 Op. cit. p. 266.

20 Entre otros pasajes Cf. En. VI 8.18.10-20, V 3.15.1-10.
} 
tomada con cautela. Desde los esquemas propios de la diferencia y la multiplicidad, la producción supone una serie de parámetros que no son aplicables al Uno. Sin

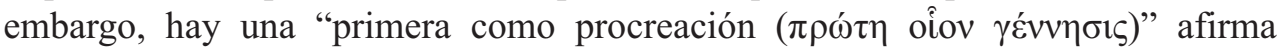
Plotino. Ontología y lenguaje se implican mutuamente en su comprensión del Uno. La inefabilidad no es solo una parte de este principio sino que subyace a cada una de las afirmaciones que permiten un discurso positivo. No hay afirmaciones por un lado y negaciones por otro, sino que cada afirmación se da simultáneamente sobre el fondo de la inefabilidad 21 y ello da un valor específico a la afirmación, un valor simbólico, como veremos. El lenguaje se ve afectado al ser llevado al límite, al acercarse a un ámbito donde el suelo sobre el que funcionan sus reglas es desfondado.

Se trata de poner en juego el origen radical de todas las cosas y de ponerlo en juego de un modo específico. No encontramos en este origen un super-ente, un ente en grado sumo sino un no-ente. Ello subvierte, en cierto modo, la ontología clásica o, mejor dicho, la delimita otorgándole un lugar subordinado, como apunta Aubenque $^{22}$. El ámbito del ser no es el primero sino que viene tras el primero y un primero que no es ser: "Lo Uno es lo primero mientras que la inteligencia, las formas y el ser no son primeros"23, afirma Plotino. Aquello que no es ser da el ser a los entes: "Todos los seres por la unidad son seres"24. Esta comprensión presenta

\footnotetext{
${ }^{21}$ En relación a esta cuestión Bréhier ("L'idée du néant et le problème de l'origine radical dans le néoplatonisme grec", op. cit., p. 255) apunta al germen de un método en Plotino. Este determina los valores más altos que podamos concebir, buscando las condiciones bajo las cuales podrían aplicarse al Principio. Tales valores están contenidos en la inteligencia y, a su través, trata de arribar al origen, donde no tienen ya significación. Apunta como ejemplo el tratamiento de la libertad que Plotino lleva a cabo en En. VI 3.6.

22 Cf. Aubenque, P. "Plotin et le dépassement de l'ontologie grecque classique", en Néoplatonisme. Colloques internationaux du Centre National de la Recherche Scientifique. Royaumont 9-13 Juin 1969. París: CNRS, 1971, p. 104. En este estudio afirma que: "Plotino es, sin ninguna duda, el primer filósofo griego que reconduce a su verdadero lugar, el segundo, a una ontología que, para responder a la cuestión del ser del ente, se contenta con exhibir un ente particular, aunque privilegiado: el Permanente, el Siempre-Existente". Si bien es cierto, como él mismo admite (op. cit., p. 105) que esta

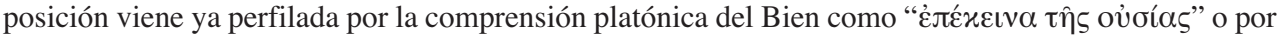
la doctrina aristotélica de que "ser" y "lo que es" no constituye un género (Metaph. 998b 22). Asimismo, "lo que es" en Aristóteles se dice en muchos sentidos, de modo que el de ousia es el primero pero no el único. A este respecto, cf. Calvo Martínez, T. "Releyendo a Aristóteles: ¿Qué, y de qué, son por sí mismas las categorías?”, Revista de Filosofía, $3^{a}$ época, vol. VIII, 1995, núm. 13, pág. 75-84.

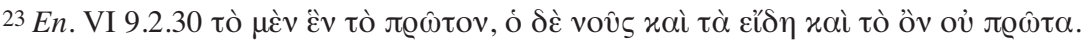

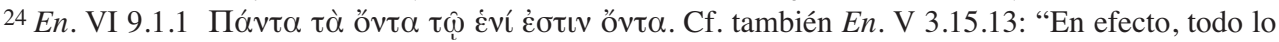
que no es uno, por la unidad se salva y por la unidad es lo que es, ya que si no se hace uno, aunque

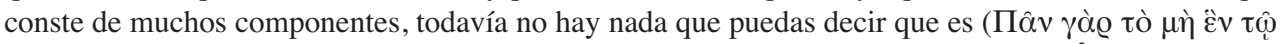

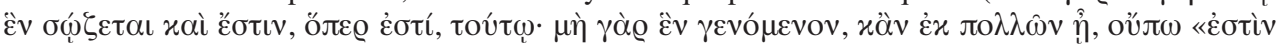

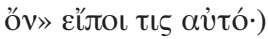


importantes retos a la reflexión con fuertes implicaciones ontológicas. Más allá de la pregunta por el proceso causal mismo a partir del cual del Uno brota la multiplicidad de lo que es ${ }^{25}$, encontramos una cuestión más fundamental: ¿qué implicaciones para lo que es tiene la comprensión de su principio como un no ente, como aquello que no es "un algo determinado"? ¿Qué ocurre con la multiplicidad cuando debe el ser a una unidad inefable?

Del Parménides platónico, Plotino toma tanto la inefabilidad de lo Uno, en la medida en que no participa del ser, como la noción del Uno-múltiple 26 , apuntando a que el ser comporta multiplicidad. Ahora bien, el prisma bajo el cual lleva a cabo la exégesis se muestra decisivo a la hora de calibrar las implicaciones ontológicas profundas que guarda en su filosofía la inefabilidad del primer principio. Como venimos viendo, el primer Uno se muestra como anterior al ser, toda vez que lo engendra ${ }^{27}$ y lo contiene a modo de padre de la esencia ${ }^{28}$.

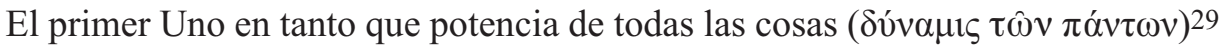
da de sí las medidas mismas de la realidad 30 y arraiga en sí mismo todo cuanto es. En su condición de principio de toda realidad no ha generado el ser desconectándolo de sí mismo. Bien al contrario, el ser permanece abierto en el núcleo mismo de su constitución a esta potencia inmensa. Plotino apunta a esta vinculación permanente en múltiples ocasiones a lo largo de las Enéadas ${ }^{31}$, en I 7.1 .30 afirma:

$\mathrm{Y}$ un buen ejemplo es el sol, pues es como un centro respecto a la luz que, dimanando de él, está suspendida de él. Es un hecho al menos que, en todas partes, la luz acompaña al sol y no está desgajada de él. Y aun cuando tratares de desgajarla por uno de los lados, la luz sigue suspendida del sol. ${ }^{32}$

25 Cf. entre otros pasajes, En. V 2.1.1-25, En.V 3.15.1-7 o V 5.5.1-28.

${ }^{26}$ Cf. En. V 1.8.24-28 pasaje en que Plotino, apuntando a la superioridad de Platón sobre Parménides en su tratamiento de los principios, se apoya en pasajes del Parménides platónico (Cf. 137c-138b, 144e5 y 155e5) llevando a cabo una lectura que se desarrolla en clave ontológica: "En cambio, el Parménides platónico, hablando con mayor exactitud, distingue unos de otros al primer Uno, que es Uno más propiamente, al Segundo, al que se llama «Unimútiple», y al Tercero, al que se llama «Uno

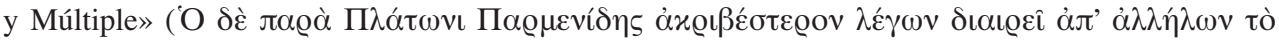

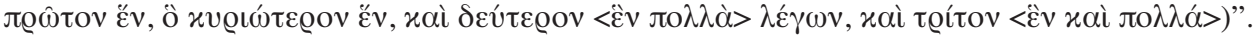

27 J. Pepin refiere esta exégesis como una transformación que Plotino impone a la doctrina platónica, apunta a que la afirmación de que el Uno es anterior al ser y lo engendra no aparece, efectivamente, en el diálogo. («Platonisme et antiplatonisme dans le traité de Plotin Sur les nombres (VI.6 [34]) », en Phronesis vol. XXIV, $\mathrm{n}^{\circ} 2,1979$, p. 204).

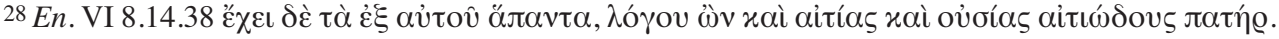

${ }^{29}$ Cf. entre otros lugares, En. III 8.10.1, IV 8.6.14 y V 3.15.30.

30 Cf. En. VI 8.18.1-5

31 Cf. por ejemplo, En. VI 5.5.10-25.

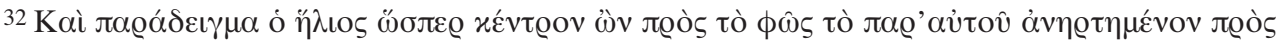

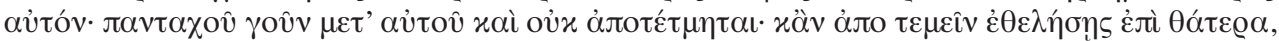

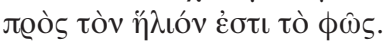


La lectura del uno de la primera hipótesis del Parménides platónico como primer principio que genera el ser y lo sostiene de modo presente en su infinita potencia otorga un calado profundo a su condición de inefable. Esta vinculación creadora permanente del primer Uno con los niveles de lo real que vienen después de él otorga a esta condición de inefable un carácter ontológico. La inefabilidad de lo Uno se extiende a la realidad entera en el núcleo mismo de su constitución inteligible.

El primer Uno es inefable en tanto que de él es negada cualquier determinación. Éste no puede funcionar como objeto de conocimiento ni ser apresado por las categorías del discurso, no es "una cosa", "un algo determinado". Plotino recoge la negación de las determinaciones respecto de lo uno que encontramos en la primera hipótesis del Parménides platónico:

Porque la naturaleza de lo Uno siendo como es progenitora de todas las cosas no es ninguna de ellas. No tiene, pues ni quididad, ni cualidad, ni cuantidad, ni inteligencia ni alma. Tampoco está en movimiento, ni tampoco en reposo, no en un lugar, no en el tiempo, sino que es «autosubsistente y uniforme», mejor dicho, aforme, anterior a toda forma, anterior al movimiento, anterior al reposo. Porque todas estas cosas son anejas al ser al que hacen múltiple. 33

Niega, así, de la naturaleza de lo Uno toda categoría y, al tiempo, pone el acento en que es "progenitora de todas las cosas". Todas las cosas encuentran su raíz, su fundamento presente, en la inefabilidad del primer principio. La realidad entera se encuentra desfondada en su núcleo mismo en esta potencia inmensa que escapa a toda categoría y a todo discurso. La inefabilidad de lo Uno es, en este aspecto, la inefabilidad de la realidad entera.

Este, en su condición de fuente originaria de lo real, confiere a todas las cosas generadas su carácter propio. En este carácter indecible, no sólo él escapa a toda categoría sino que, con él, cada ser generado escapa a toda categorización, en el núcleo mismo de su naturaleza. En cada uno de los seres, en tanto que generados por esta potencia inefable, habita un aspecto que escapa a toda objetivación, a toda posibilidad de posesión.

Plotino sigue de cerca el Parménides platónico 34 negando respecto del primer Uno cualquier figura, profundizando en la dimensión ontológica de esta afirmación. Éste pone de relieve las implicaciones que se siguen de esta condición para los seres generados, en tanto que incardinados en esta potencia creadora que carece de forma. Así en Enéadas VI 7. 32.7-22 afirma:

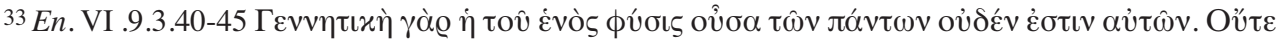

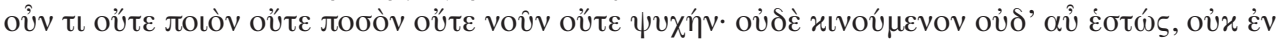

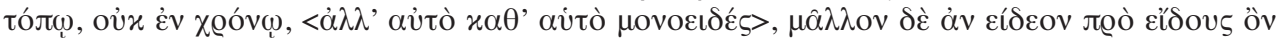

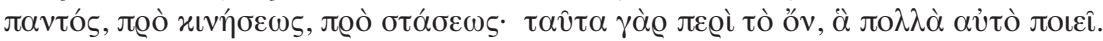

34 Prm. 137 e 1. 
Ahora bien, el Principio debe ser lo sin forma: no necesitado de forma, sino el Principio de donde proviene toda conformación intelectiva. Porque lo llegado a ser, si en llegando a ser, tenía que llegar a ser «algo», asumió una conformación individual. Pero lo que nadie hizo, ¿quién podría hacerlo «algo»? Por lo tanto el Principio no es ninguno de los seres y es todos los seres: ninguno, porque los seres son posteriores; todos, porque provienen de él. [...] Además, el hecho de que exista por siempre y se extienda a todas las cosas no pone medida en él, aunque tampoco pone en él desmedida. ¿Cómo, si no, podría medir las demás cosas? Por lo tanto, tampoco tiene figura. ${ }^{35}$

Inmediatamente después, Plotino introduce la consecuencia que se sigue para los seres generados. Esta ausencia de forma del Progenitor de la Belleza es la ausencia de forma de los seres que provienen de él, en tanto que arraigados en esta Potencia inmensa que carece de forma: "Siendo Principio de la Belleza, hace bello a aquello de lo que es Principio; mas lo hace bello sin imponerle una forma. Bien al contrario, hace que aun lo engendrado carezca de forma."36

El marco de comprensión de lo real que dibuja Plotino gira en torno a la inefabilidad de lo uno planteada en el Parménides platónico. Esta inefabilidad es ubicada en el corazón mismo de la realidad, latiendo en cada perfil y en cada forma, otorgando un sentido trascendente a todo cuanto es. La realidad entera toma, así, la condición de imagen 37 de una potencia inmensa transmisora de una belleza que no tiene

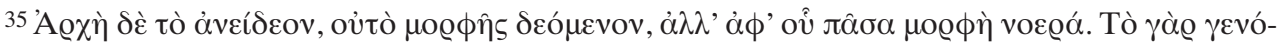

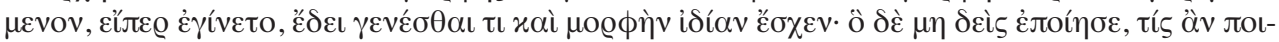

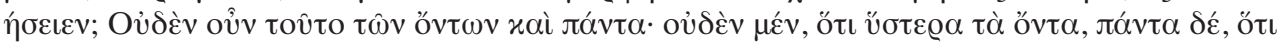

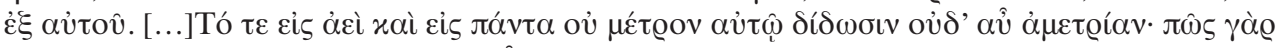

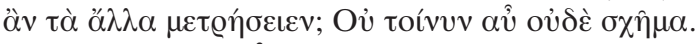

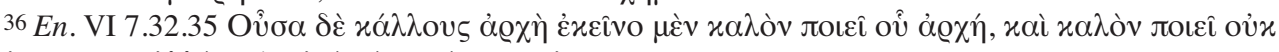

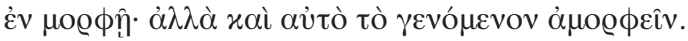

37 Todos los seres son huellas del Uno. Estos se conforman en expresión activa que hunde sus raíces de modo presente en aquello que están manifestando, confiriendo una faz manifiesta a la ingente potencia creadora del Principio. La imagen, en este sentido, no ha de ser concebida como un doble de otra realidad más real situada en otro lugar. No hay lugar alguno en el que pueda habitar la causa

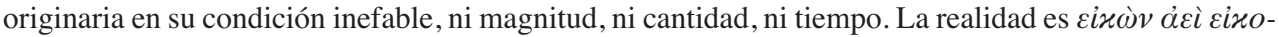

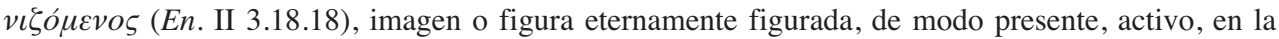
recepción de una energía creadora que no tiene tiempo. Esta convergencia de la inefabilidad del Principio y del carácter expresivo de la imagen confiere a lo real un carácter simbólico que ha de observarse de modo privilegiado en la belleza. Ésta será en la filosofía de Plotino una de las vías privilegiadas que facilitan el acceso a lo inefable, más allá de todo lugar, de todo tiempo, de toda categoría y de todo discurso (A este respecto, Cf. el excelente estudio de Narbonne J-M. «La quête du beau comme itinéraire intérieur chez Plotin» en Cahiers du centre d'études sur la pensée antique «kairos kai logos», 10, 1997: 1-16). Por otra parte, esta noción de la belleza como ámbito mediador en el que converge la forma y aquello que no tiene forma constituirá el mimbre de comprensión de lo simbólico en el pensamiento de Jámblico. Sobre este punto, Cf. Hermoso, M.J. El símbolo en el De Mysteriis de Jámblico: La mediación entre el hombre y lo divino. Madrid: U.C.M. 2012.
} 
forma: "Porque el rastro de lo carente de forma es la forma. Es un hecho, al menos, que lo carente de forma engendra la forma" 38 , afirma Plotino.

De este modo, la inefabilidad del Uno conforma una nota imprescindible para su condición de Principio. Esta constituye la piedra angular y el núcleo de un sistema que afecta a la realidad entera. Ambas notas tomadas conjunta y simultáneamente ofrecen una comprensión de lo real que lleva hasta sus últimas consecuencias elementos que, como hemos señalado ${ }^{39}$, están ya presentes en el pensamiento de Platón y Aristóteles. Con ello, Plotino afina y lleva la ontología clásica más allá de sí misma. En cierto sentido, podemos afirmar con Aubenque 40 que en su filosofía se prefiguran elementos presentes en el proyecto contemporáneo de superación de la ontología clásica.

Esta reflexión es central a la hora de contemplar el pensamiento de Plotino desde una perspectiva actual y muy acertada si la tomamos con cautela. Sería completamente anacrónico afirmar que Plotino busca superar y mucho menos deconstruir la ontología clásica, en su espíritu está el otorgarle un rango propio, subordinándola a su comprensión del primer Uno como principio inefable. Busca con ello ofrecer la exégesis más acertada de la filosofía platónica. Una cosa sí es cierta, su filosofía escapa a muchas de las críticas que se han dirigido a la ontología clásica y a la metafísica desde pensamientos como el de Heidegger y deja constancia de un modo de alternativo de tratar el problema.

Heidegger llega a trazar la historia de la Metafísica como la historia de un error, una especie de pecado original del pensamiento occidental. A la pregunta por el ser del ente se habría ofrecido una respuesta a través del mundo, entendido como conjunto de los entes, se habría abandonado el ser a la entidad. La Metafísica sería un olvido del ser ${ }^{41}$, constreñido por la comprensión del ente como presencia y, correlativamente, del pensar como re-presentar 42 .

Este ha trazado como pocos las consecuencias que se siguen de este "olvido del ser" para el mundo de los entes. Finalmente este abandono culminaría en la técnica como modo de disponibilidad completa del ente por una voluntad omnímoda, por una voluntad de voluntad que se vehicula a través de una organización total de la

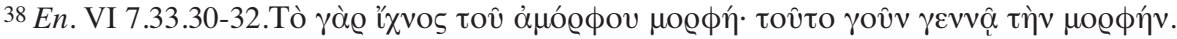

39 Supra, n. 22.

40Aubenque, P. "Plotin et le dépassement de l'ontologie grecque classique", en Néoplatonisme. Colloques internationaux du Centre National de la Recherche Scientifique. Royaumont 9-13 Juin 1969. París: CNRS, 1971, p. 107-108.

${ }^{41}$ Cf. entre otros lugares Heidegger, M. Ser y tiempo (trad. castellana de Rivera J.E.). Madrid: Trotta, 2003 , I 6, 22. Este olvido del ser sería, ante todo, un olvido de la pregunta por el ser, que habría sucumbido a una tradición que la relega a la condición de cosa obvia. Se ha obviado la pregunta y con ella la esperanza de recuperar una experiencia original que rescate al ente mismo del olvido del ser.

${ }^{42}$ Cf. Heidegger, M. “¿Qué quiere decir pensar?”, en Conferencias y artículos (trad. castellana Barjau, E.) Barcelona: Odos, 1994, p. 124.
} 
vida $^{43}$. Sus reflexiones no dejan indiferente al hombre contemporáneo que, tras las guerras mundiales, ha vivido los efectos de una técnica mal orientada y de una capacidad macabra de organización y de movilización total.

La reducción del ser a la entidad tiene una consecuencia para el ente: este se ofrece a una completa disponibilidad, nada hay en él que no esté dispuesto a una libre disposición por una voluntad de voluntad. Hombre y mundo salen empobrecidos en este comercio que Heidegger denomina "usura del ente"44. Ante este panorama, aboga por la necesidad de llevar a cabo una "destrucción, hecha al hilo de la pregunta por el ser, del contenido tradicional de la ontología antigua" 45 , esta destrucción dejaría, por fin, al descubierto la búsqueda de una experiencia originaria.

Plotino abre en su época otra vía que respeta la ontología clásica y la afina hasta ubicarla claramente en un lugar subordinado que evita precisamente esta reducción del ser del ente a la entidad ${ }^{46}$, aun a la más excelsa de ellas. Aquello que otorga el ser a lo que es no es una super-entidad, sino un no-ente, un no-algo, un no-esto, un no-representable por el lenguaje. Aquí el hombre podría enmudecer y renunciar a seguir indagando o hundirse en el abismo de lo irracional. Nada de eso ocurre en el pensamiento de Plotino ${ }^{47}$. Su genio abre esta condición precisamente como camino, legando algunas de las líneas más extraordinarias de la filosofía occidental.

43 Heidegger, M. "Superación de la Metafísica”, op. cit. p. 72 ss.

44 Op. cit. p. 86.

45 Heidegger, M. Ser y tiempo (trad. castellana de Rivera J.E.). Madrid: Trotta, 2003, I 6, 22-23.

46 Es cierto, como afirma P. Hadot (Porphyre et Vitorinus, I, París : Études Agustiniennes, 1968, p. 490, n.2), y como reconoce Aubenque (op. cit, p. 107), que no encontramos "ningún trazo en Plotino de una distinción entre ser y ente". La distinción, tipificada específicamente, entre la noción de un serinfinitivo (Eîvol) y un ser-participio (ǒv) o los sustantivos que designan la sustancia la encontraríamos por primera vez en un comentario neoplatónico al Parménides de Platón que P. Hadot atribuye a Porfirio. Sobre esta cuestión, Cf. P. Hadot "L'être et l'étant dans le néoplatonisme" en Études néoplatoniciennes, Neuchatel: La Baconnière, 1973, p. 27-39. Si bien Plotino, como también señala Aubenque, en En. VI 9.1.1 se pregunta por lo que hace ser a los seres, respondiendo que lo que hace ser a lo que es, es el uno. Quiebra con ello la posibilidad de comprender "lo que hace ser" como una entidad, delimitando una vía de comprensión alternativa a la que Heidegger atribuye a la ontología antigua.

47 Dodds (op. cit., p. 140-141) pone el acento en este carácter no irracional del pensamiento de Plotino. Su genio consiste, precisamente en explorar los límites de la razón, sin caer en su contrario, trazando una culminación supra-racional del conocimiento. Este punto vuelve a plantear la cuestión de las posibles influencias de tradiciones orientales sobre el planteamiento de Plotino (Cf. supra n.6). Esta vez al hilo de la teoría del éxtasis. Dodds admite que en ningún lugar es tan manifiesta la genialidad de Plotino como en su teoría del éxtasis, que tiene como correlato su doctrina del Uno. Si el Uno trasciende todas las categorías del pensar el acceso a él solo puede ser supra racional. Como bien explica Dodds (op.cit, p.141) "El supremo acto de cognición no será, por tanto, estrictamente cognitivo en absoluto, sino que consistirá en la momentánea actualización de la potencial identidad entre el Absoluto en el hombre y el Absoluto fuera del hombre". Nuevamente nos encontramos a Dodds reclamando la naturaleza griega de esta hipótesis, apoyándose en la teología negativa del Parménides y en la República platónica. Apuesta por una diferenciación abierta entre el éxtasis plotiniano y otros tipos 
Esta comprensión no lleva a una vía muerta en la que el hombre haya de renunciar a percibir o a hablar sino que el sentido mismo de la percepción y del lenguaje queda subvertido en un espacio donde no hay nada disponible, nada que re-presentar, nada que poseer, nada con lo que comerciar. En este punto empieza para el Neoplatonismo el verdadero caminar del filósofo por tierra incógnita, una tierra donde él mismo se pone en juego. Los seres son una huella del Uno, "lo que es" ha dejado de estar por completo disponible, la realidad entera ha recuperado esa faz inefable en la que administración técnica, re-presentación, organización total de la vida carecen de sentido.

\section{Inefabilidad del primer principio y comprensión del lenguaje}

Las consecuencias de la inefabilidad del primer Uno en el ámbito ontológico tienen su correlato en la comprensión del lenguaje. Si el Uno escapa a toda determinación objetiva, si no hay un "algo", un "esto", el lenguaje y sus categorías carecen de aplicación 48 . El lenguaje a este nivel no podrá ser concebido como espacio de re-presentación, no tendrá como finalidad delimitar la naturaleza del Primer principio. Ni siquiera el discurso negativo acerca del Uno dice nada de él, dice lo que no es, contrapesa cualquier afirmación, poniendo de manifiesto su inadecuación, pero no lo expresa a él mismo 49 . Nada hay que pueda funcionar como denominación del Uno. La cuestión es si ello llevaría a la imposibilidad de utilizar el lenguaje, a una especie de mutismo o si el lenguaje toma entonces un valor específico.

Plotino no abre a partir de la inefabilidad del Uno un abismo irracional sino que continúa utilizando el lenguaje, llevándolo al límite, advirtiendo que el lenguaje no nombra nada cuando se trata de hablar del Uno. El silencio necesario que se acompasa con la inefabilidad del Uno no deja sin espacio al lenguaje sino que le otorga un lugar propio. El silencio ante el Uno no es el silencio del que ignora sino un silencio que acontece tras un largo camino a través de las mediaciones que facilitan ese acercamiento. No se niega, por tanto, el valor del lenguaje sino que se ubica en un lugar propio. El lenguaje no re-presenta cuando se trata del Uno pero tampoco se cierra sobre sí mismo sino que adquiere un carácter orientado a la experiencia.

\footnotetext{
de éxtasis como el de Filón o el de otros pensadores de la línea neoplatónica como Jámblico, que serían claramente irracionales, a los que no duda en vincular con lo que él llama "trance mediúmnico". Creemos que en el caso de Jámblico la exégesis es muy apresurada y no toma en cuenta elementos fundamentales de su pensamiento que no se dejan enmarcar en esa comprensión (Cf. Hermoso, M.J. op.cit., p. 428-439). Por otro lado, estudiosos como Bréhier son partidarios de tomar en cuenta una probable influencia oriental del pensamiento de Plotino. A este respecto, Cf. Bréhier, É. La philosophie de Plotin. París: Vrin, 1999, p. 107 ss. Asimismo, Cf. el interesante estudio de García Bazán F. Neoplatonismo y Vedânta. Buenos Aires: Depalma, 1982.

48 Cf. Beierwaltes, W. Plotino (trad. italiana de E. Peroli). Milán: Vita e pensiero, 1993, p. 52-57.

${ }^{49} \mathrm{En}$. V 3.14.1-15.
} 
La inefabilidad del Principio primero de la realidad tiene en el pensamiento de Plotino una consecuencia epistémica profunda: El verdadero camino de la filosofía no se juega en el discurso 50 ya que el misterio último que fundamenta lo real y lo acoge en su seno trasciende toda categoría discursiva. La facultad discursiva del alma establece siempre una distancia categorizadora sobre su objeto tras la que se pierde el acceso a su sentido profundo. Un sentido que solo puede ser desvelado en el interior del alma a través de una unificación progresiva. La filosofía se torna, entonces, itinerario de transformación de la percepción, de refinamiento y de equilibrio de la mirada del alma.

El centro sobre el que gravita la actividad filosófica no es el discurso, aunque conforma una parte importante de la misma siempre que tome consciencia de su propio límite. Cuando se trata del Uno el lenguaje es objeto de una reflexión que lo limita y le otorga un lugar propedéutico ${ }^{51}$, mediador. En Enéadas V 3.13.1 leemos:

Porque digas lo que dijeres dirás algo. Pero la expresión «más allá de todas las cosas y más allá de la inteligencia más augusta» 52 entre todas es sólo verdadera no si es una denominación de Aquél sino si Aquél no es uno entre todos ni hay «nombre de Él» ${ }^{53}$, porque nada se predica de Él. Pero nosotros tratamos de señalárnoslo a nosotros mismos como podemos. 54

El discurso deja de funcionar como un ámbito de re-presentación, ninguna categoría es capaz re-presentar y transmitir aquello que trasciende toda categoría. El

\footnotetext{
50 Acerca del carácter del discurso en la filosofía de Plotino, cf. Hadot P. Qu'est-ce que la philosophie antique? París: Gallimard, 1995, p. 251-259; O’Meara D. Une introduction aux Ennéades. Fribourg : Cerf, 1992, p. 71-78 (Traducción francesa de Callet-Molin A.) y Charles-Saget A. L'Architecture du divin. Mathématique et Philosophie chez Plotin et Proclus. París : Les Belles Lettres, 1982, p. 302307.

51 El discurso acerca del Bien forma parte de un aprendizaje previo pero no ha de ser confundido con la experiencia. En En. VI 7.36.5-15 afirma Plotino que: "Las analogías, las negaciones, el conocimiento de los provenientes de él y los grados escalonados nos instruyen acerca de él. [...] Pero quienquiera que logre hacerse espectador y espectáculo a un tiempo, él mismo de sí mismo y de las demás cosas, al convertirse con ello en Esencia, en Inteligencia y en Viviente perfecto, ya no verá a este viviente

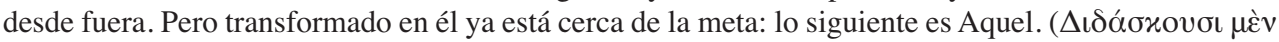

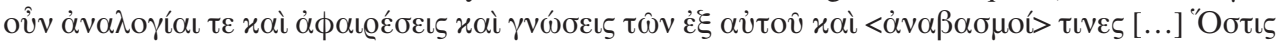

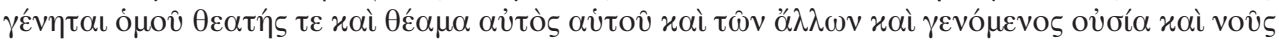

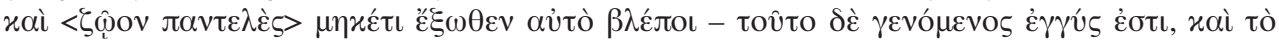

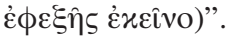

52 Pl. R. 509 b 9.

$53 \mathrm{Pl}$. Prm. 142 a 3.

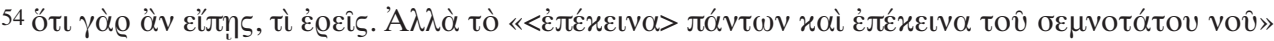

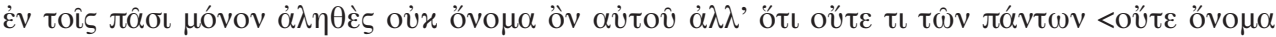

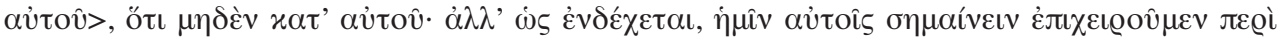

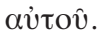


lenguaje mira hacia nosotros que "tratamos de señalárnoslo a nosotros mismos

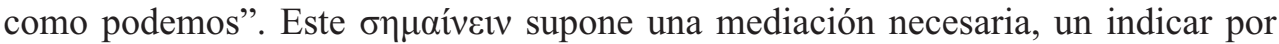
medio de símbolos. El lenguaje mismo deviene simbólico cuando se trata de apuntar a aquello que es indecible 55 .

El espacio del discurso no es desdeñable, no se trata de proponer un espacio de irracionalidad que niegue el valor de lo discursivo. Antes bien, se trata de mostrar que toda afirmación es sólo posible si se sabe a sí misma limitada, inadecuada; si aparece como condicionada y provisoria. Silencio y discurso se dan la mano: El silencio es lo más apropiado para el Uno, el discurso es el flanco humano de una experiencia que lleva al hombre más allá de sí, a lo más íntimo de sí. Ambos se complementan, de modo que el discurso filosófico emerge, en última instancia, desde el silencio de "aquel dios calladamente presente" 56.

Beierwaltes pone de manifiesto el efecto anti-dogmático ${ }^{57}$ de esta comprensión de la experiencia y del lenguaje. Todo cuanto se dice podría ser expresado de otra manera, toda afirmación comporta simultáneamente una negación. La verdad de lo expresado en el lenguaje apunta a la mirada del hombre, es siempre una interpretación de la experiencia filosófica.

La inefabilidad del Uno tiene, como apunta Bréhier ${ }^{58}$, un reverso positivo. El Primero se constituye para Plotino en centro de la vida afectiva: "El aspecto negativo del Uno en cuanto al conocimiento es, por tanto, el reverso de un aspecto positivo, de esa suerte de ola creciente que nos lleva hasta nosotros mismos e incluso, más allá de nosotros mismos". La inefabilidad del Principio al nivel del conocimiento y del lenguaje no abre un abismo insondable. Este no puede ser re-presentado en el discurso pero eso no significa que no podamos tenerlo de ningún modo, afirma Plotino. En Enéadas V 3.14.6-10 se pregunta:

¡Cómo! Si no lo tenemos por el conocimiento, ¿quiere decir que no lo tenemos en modo alguno? Lo tenemos como para poder hablar acerca de Él, pero no como para poder expresarlo a Él mismo. Y es que decimos lo que no es, pero lo que es no lo decimos. Así que hablamos de Él a partir de los posteriores. Con todo, no se nos impide que lo tengamos aunque no lo expresemos, sino que del mismo modo que los entusiasmados y

\footnotetext{
55 Son muchos los estudiosos que han señalado, de una u otra manera, la importancia del símbolo en el pensamiento de Plotino y el carácter simbólico que toma su lenguaje. Pepin en su estudio ya clásico Mythe et allégorie se refiere a la filosofía de Plotino como una filosofía de lo indecible que, en la medida en que quiere expresarse y transmitirse, ha de utilizar la expresión simbólica. Cf. Pepin, J. Mythe et allégorie. Les origines grecques et les contestations judéo-chrétiennes, París: Études Augustiniennes, 1976, p. 190 ss.

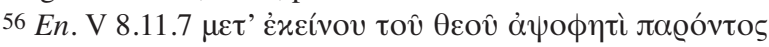

57 Op. cit. p. 54.

58 Bréhier, E. "Le Parménide de Platon et la Théologie négative de Plotin”, en Études de Philosophie Antique. París: Presses Universitaires de France, 1955, p. 233.
} 
los inspirados pueden llegar a saber ni más ni menos que esto: que tienen en sí mismos algo superior a ellos aun cuando no sepan quién es. 59

El alma, y no el discurso, constituye el centro de la actividad filosófica. Ésta, como afirma Trouillard, será siempre el gran problema en torno al cual gire el saber filosófico para toda la tradición platónica: "El gran problema de la filosofía es el conocimiento de sí y el único campo de la investigación filosófica es el alma: Esta es la sede de toda presencia"60. Este es el laboratorio del filósofo y a la experiencia que tiene lugar en este ámbito se refiere toda especulación filosófica.

El discurso filosófico en Plotino no tiene como primera finalidad re-presentar la realidad, ni determinar categorialmente sus principios, no pretende poseer una verdad objetiva acerca de cómo es lo real o cómo es el alma. La verdad, en toda la tradición platónica, se halla en la mirada del sabio, sólo allí se verifica la orientación del discurso que ha de ser siempre dinámico, paradójico, dispuesto a la metamorfosis. El lenguaje busca quebrar su propio límite para servir al alma de vehículo de expresión de una experiencia que trasciende toda categoría.

La filosofía de Plotino, partiendo de su exégesis de la inefabilidad de lo uno planteada en el Parménides platónico, concibe el discurso filosófico como una hermenéutica de la experiencia:

Y es que aún el llamarle < causa $>$ no es predicar algo que le sucede a él sino a nosotros, porque tenemos algo recibido de él, estando aquél en sí mismo. Pero hablando con propiedad, no hay que decir ni <aquél $>$ ni $<$ estando $>$, sino, rondándolo desde fuera, por así decirlo, tratar de interpretar nuestras propias experiencias. ${ }^{61}$

Tras la negación de la posibilidad de aplicar con propiedad al Uno cualquier denominación, cualquier categoría, se esconde un giro del lenguaje y de la propia filosofía, que no busca ya decir nada del Uno sino conducir a él y expresar e "interpretar nuestras propias experiencias". Como afirma O’Meara62: "El discurso sobre el Uno es un discurso sobre nosotros mismos". Un discurso que hace referencia a nosotros mismos en un doble sentido: un sentido propedéutico, de preparación, de

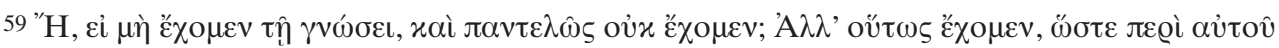

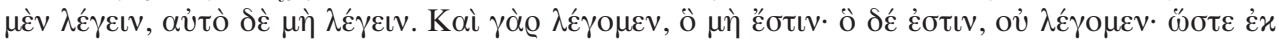

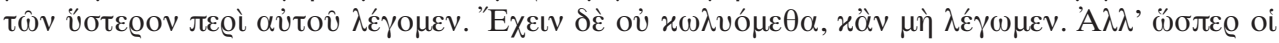

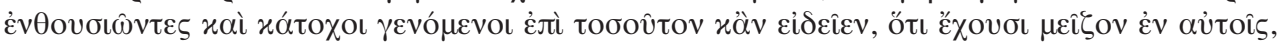

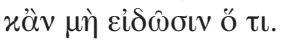

60 Trouillard J., op. cit. p. 120.

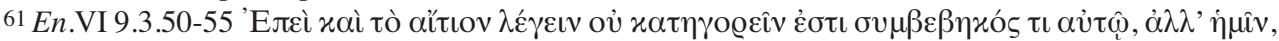

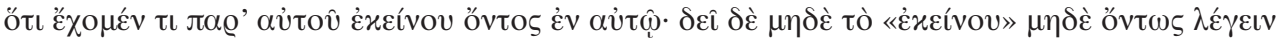

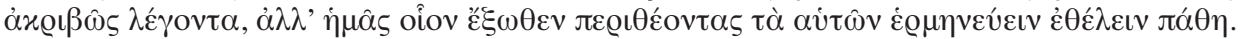

62 O'Meara, D. "Le problème du discours sur l'indicible chez Plotin", Revue de Théologie et de Philosophie, 122, 1990, p. 151. 
mediación, de guía hacia la experiencia y un segundo sentido referido a la expresión e interpretación de la experiencia.

Antes y después de lo inefable el hombre necesita del discurso. El lenguaje tiene un carácter anagógico, lleva de la mano hacia aquello que el hombre debe contemplar por sí mismo y después ayuda al hombre a interpretar y expresar aquello que no es categorizable. Lo Uno inefable se propone al hombre como tarea que solo puede cumplirse con la ayuda de la palabra que linda siempre con el silencio, que lo hace posible y soportable para el hombre. El pensamiento de Plotino se mueve en esa frontera entre lo divino y lo humano que demarca el territorio del platonismo, trata de hacerla transitable sin reducción ni sustitución. Finalmente se trata de explorar las posibilidades del lenguaje más allá de una lógica estrecha, de abrir las posibilidades de la significación haciendo emerger el espacio de lo simbólico y su verdad63.

\section{Conclusiones}

Las consecuencias que extrae Plotino de su lectura del carácter inefable del uno de la primera hipótesis del Parménides tienen una vertiente teórica que sostiene los mimbres mismos de su pensamiento en sus latidos más básicos. Ahora bien, a esta vertiente se añade, de modo intrínseco, una vertiente eminentemente práctica que sustenta su comprensión del lenguaje y de la filosofía. Esta vertiente es profundamente significativa ya que viene a determinar la disposición que hemos de tomar en la exégesis misma de los textos.

La inefabilidad de lo Uno, que es ubicada por Plotino en el núcleo mismo de su sistema, tiene implicaciones profundas a nivel ontológico. La comprensión de la realidad como huella del Uno inefable y el lugar subordinado de la ontología son algunas de las más señaladas. Estas implicaciones a nivel ontológico tienen su contrapartida en la compresión de la naturaleza del discurso. El lenguaje y sus categorías no son aplicables a aquello que no es "un algo" determinado. El discurso a este nivel no busca re-presentar cuanto conducir e "interpretar nuestras propias experiencias".

El centro de la actividad filosófica gravita en torno a ese Uno inefable, limitando el alcance y la significación del discurso ${ }^{64}$. Éste no busca tanto ser objetivo: nada

\footnotetext{
63 Aubenque tiene toda la razón al referirse a Wittgenstein en este contexto: "Este afirma que «de lo que no se puede hablar es mejor guardar silencio», pero enseguida añade que lo indecible puede, no obstante «mostrarse». Los neoplatónicos no dicen otra cosa, con una única salvedad, a saber: que, cultivando sistemáticamente las posibilidades del lenguaje, se siguen esforzando en mostrar por medios lingüísticos lo que saben que no puede ser dicho en forma de aserciones lógicamente administrables" ("La superación neoplatónica de la Metafísica”, en ¿Hay que deconstruir la Metafísica? (trad. castellana Ayuso Díez, J.M.). Madrid: Encuentro, 2012, p.53).

64 Cf. por ejemplo, En. VI 9.4.13-16.
} 
hay que apresar en el objeto cuando se trata de acceder a su sentido constituyente; cuanto conformarse en hermenéutica de una experiencia actual, capaz de entregar al alma el sentido inefable de lo real, sosteniendo la belleza de las formas y la armonía del mundo.

La inefabilidad del Primer Principio afecta a la comprensión misma del camino que plantea la filosofía de Plotino. Esta no busca añadir nada ${ }^{65}$, ningún conocimiento predicativo, ninguna creencia, ningún esquema preconcebido. Por el contrario, busca sentar las mediaciones que faciliten el despojamiento del alma, su unificación con una realidad que no puede ser vertida en el discurso. La filosofia trata de sostener al alma en un itinerario que busca el desasimiento de todas las cosas, acompañando a la inefabilidad del Uno:

-Basta, sin embargo, con que haya un contacto, aunque sea intelectivo, y que, tras el contacto, no haya posibilidad ni holgura para poder decir una sola palabra en el momento mismo del contacto, sino que sea más tarde cuando se recapacite sobre aquella experiencia. $[\ldots]$

He aquí la meta verdadera del alma: el tocar aquella luz y contemplarla con esa misma luz; no con la luz de otro, sino contemplar la misma luz por la que ve. Porque la luz por la que fue iluminada, es la luz que debe contemplar, ya que ni siquiera al sol lo vemos con luz ajena.

-Y esto ¿cómo se puede lograr?

-¡Despójate de todo! 66

Lo Uno, siendo inefable, no es inalcanzable por el alma, siempre que ésta se abra a esta inefabilidad más allá de toda categoría, de todo tiempo, de todo discurso. La mirada unificada que emerge en esta disposición no es irracional, ni niega el discurso y su valor. Antes bien, tiene el poder de ubicar el ámbito de lo discursivo en su lugar propio, limitando su alcance y reclamando hacia él una disposición siempre dinámica, consciente de que el estadio de la filosofía, su campo de actividad y de ejercicio, no se halla en las categorías del discurso. Los juegos olímpicos a los que aspira el filósofo serán siempre, como decía Porfirio, los juegos olímpicos del alma. A estos el filósofo ha de ascender "desnudo y sin túnica"67, buscando des-

65 Cf. entre otros pasajes, En. VI 9.4.25-30 o VI 7.34.1-10.

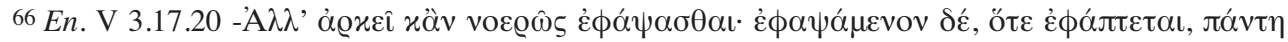

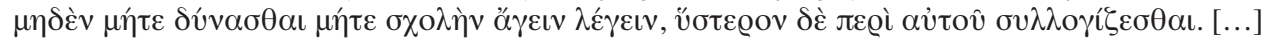

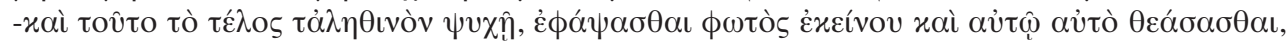

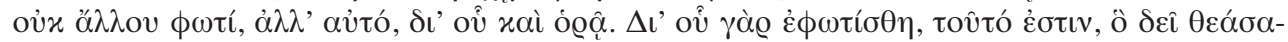

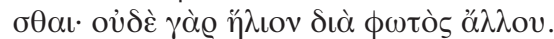

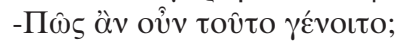

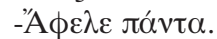

${ }^{67}$ Porph. Abst. 1.31.3. 
pojarse de todo para arribar a una "identidad sin color ni cualidad" en la que la inefabilidad del Uno está dada en su verdadera dimensión y calado.

\section{Referencias bibliográficas}

\section{Fuentes}

Platón: Platonis Opera, I-V, ed. J. Burnet, Oxford: Clarendon Press, 1961.

Platón: República, (trad. de Pabón J.M. y Fernández-Galiano M. Platón). Madrid:

Centro de estudios políticos y constitucionales, 1997.

Platón: Fedón, Banquete, Fedro, (introd., trad. y notas de C. Carcía Gual, M. Martínez y E. Lledó). Madrid: Gredos, 1986.

Platón: Parménides (trad. María Isabel Santa Cruz). Madrid: Gredos, 1988.

Plotino: Plotini Opera, 3 vols., Henry P. y Schwyzer H. R. (eds.), Lovaina, París, Leiden: Desclée de Brower- E.J. Brill, 1951-1973 (edition maior).

Plotino: Plotini Opera, 3 vols., Henry P. y Schwyzer H. R. (eds.), Oxford: Clarendon Press, 1964-1982 (editio minor).

Plotino: Plotin. Ennéades, 7 vols., ed., trad. y notas E. Bréhier, París: Les Belles Lettres, 1924.

Plotino: Plotino. Enéadas I-VI, 3 vols., introd., trad. y notas de J. Igal, Madrid: Gredos, 1982-1998.

\section{Estudios}

Aubenque, P.: "Plotin et le dépassement de l'ontologie grecque classique", en Néoplatonisme. Colloques internationaux du Centre National de la Recherche Scientifique. Royaumont 9-13 Juin 1969. París: CNRS, 1971, pp. 101-109.

AubenQue, P.: "La superación neoplatónica de la Metafísica”, en ¿Hay que deconstruir la Metafisica? (trad. castellana Ayuso Díez, J.M.). Madrid: Encuentro, 2012, pp. 43-54.

Beierwaltes, W.: Plotino (trad. italiana de Peroli, E.). Milán: Vita e pensiero, 1993. BeIERWAltes, W.: Autoconoscenza ed esperienza dell'Unità (trad. italiana Trotta, A.). Milán: Vita e pensiero, 1995.

Beierwaltes, W.: Pensare l’Uno. Milán: Vita e pensiero, 1992.

BrÉHIER, É.: “Le Parménide de Platon et la Théologie négative de Plotin", en Études de Philosophie Antique. París: Presses Universitaires de France, 1955, pp. 232-236.

BRÉHIER, É.: “L'idée du néant et le problème de l'origine radical dans le néoplatonisme grec", op. cit., pp. 248-287.

BrÉHIER, É.: La philosophie de Plotin. París: Vrin, 1999

Calvo Martínez, T.: “¿Qué, y de qué, son por sí mismas las categorías?, Revista de Filosofía, $3^{\text {a }}$-época, vol. VIII, 1995, núm. 13, pág. 75-84. 
Charles-Saget, A.: L'Architecture du divin. Mathématique et Philosophie chez Plotin et Proclus. París : Les Belles Lettres, 1982

Chrétien, J. L.: “Le Bien donne ce qu'il n'a pas”, Archives de Philosophie, n 43, 1980, pp. 263-278.

Dodds, E.R.: "The Parmenides of Plato and the Origin of the Neoplatonic One",

The Classical Quarterly, Vol. 22, no 3/4 (Jul.-Oct., 1928), pp. 129-142.

García BazÁn, F.: Neoplatonismo y Vedânta. Buenos Aires: Depalma, 1982.

Hadot, P.: Qu'est-ce que la philosophie antique? París: Gallimard, 1995.

HADOT, P.: "L'être et l'étant dans le néoplatonisme" en Études néoplatoniciennes,

Neuchatel: La Baconnière, 1973, p. 27-39

Hadot, P.: Porphyre et Vitorinus, I, París : Études Agustiniennes, 1968.

HeIdegGer, M.: Ser y tiempo (trad. castellana de Rivera J.E.). Madrid: Trotta, 2003.

Heidegger, M.: "Superación de la Metafísica", en Conferencias y artículos (trad.

castellana Barjau, E.) Barcelona: Odos, 1994, pp. 63-89.

HeIDEgGer, M.: “¿Qué quiere decir pensar?”, op. cit. pp. 113-142.

Hermoso, M.J.: El símbolo en el De Mysteriis de Jámblico: La mediación entre el hombre y lo divino. Madrid: U.C.M. 2012.

NARBonne, J-M.: «La quête du beau comme itinéraire intérieur chez Plotin» en Cahiers du centre d'études sur la pensée antique «kairos kai logos», 10, 1997 : 1-16.

O'Meara, D.: “Le problème du discours sur l'indicible chez Plotin", Revue de Théologie et de Philosophie, 122, 1990, p.145-156.

O’MearA, D.: Une introduction aux Ennéades. Fribourg : Cerf, 1992.

PEPIN, J.: «Platonisme et antiplatonisme dans le traité de Plotin Sur les nombres (VI.6 [34]) », en Phronesis vol. XXIV, n², 1979, p. 204.

PEPIN, J.: Mythe et allégorie. Les origines grecques et les contestations judéo-chrétiennes. París: Études Augustiniennes, 1976.

Rist, J. M. "The Neoplatonic One and Plato's Parmenides", Transactions and Proceedings of the American Philological Association, Vol. 93 (1962), pp. 389401.

Trouillard, J. L'un et l'âme selon Proclos. París: Les Belles Lettres, 1972.

Zamora, J.M. La génesis de lo múltiple. Materia y mundo sensible en Plotino. Valladolid: Universidad de Valladolid, 2000.

María Jesús Hermoso Félix

Universidad de Valladolid

mjhermosofelix@yahoo.es 